\title{
Mechanical behavior of post-installed anchorage between steel and concrete under high temperature
}

\author{
Song XUE'1, a, Qun XIE ${ }^{1, b}$ and Ping-ping GUAN, c \\ ${ }^{1}$ School of Civil Engineering and Architecture, University of Jinan, Nanxinzhuang West Road, 336, \\ Ji nan 250022, China \\ a1776380389@qq.com, bcea_xieq@ujn.edu.cn, c2236049480@qq.com
}

\begin{abstract}
Keywords: Post-installed Anchorage, 3D Joint Model, ABAQUS, High Temperature.
Abstract. As a reliable technology for connecting a new steel element to the existing concrete structures, the post-installed anchorage is widely used in the field of structural retrofit and strengthening. In order to analyze the mechanical behavior of post-installed anchorage between steel and concrete under high temperature, the numerical simulation is carried out by ABAQUS software in this paper. Several 3D joint models of I-shaped steel beam connecting to concrete base are established with consideration of two parameters, the thickness of fire protection and embedment depth of bonded-in reinforcements. The natural fire curve and the inorganic adhesive are adopted. The results have been discussed and analyzed in the context of temperature field, load-displacement relationship at loading point and longitudinal displacement of bonded-in reinforcements. The results showed that the maximum temperature of bonded-in reinforcements could be controlled below $250^{\circ} \mathrm{C}$ if the thickness of fire protection is added up to $40 \mathrm{~mm}$. A calculation method is proposed by model data to predict the maximum temperature of bonded-in reinforcements. Both larger embedment depth and thicker fire protection can improve the residual bearing capacity of the joint after exposed to fire. The employment of inorganic adhesive has been verified to be an effective method to improve the bond performance between bonded-in reinforcements and concrete under high temperature.
\end{abstract}

\section{Introduction}

Post-installed anchorage is a widely used technology where a new steel element needed to connect with the existing concrete structure especially in the field of structural retrofit and strengthening. The post-installed anchorage is generally assembled by inserting several anchors or rebars into predrilled holes in hardened concrete. The load transfer between the anchor and the concrete in mechanical anchors is mainly achieved by either bearing or through friction whereas in adhesively bonded anchors load transfer occurs through shearing of adhesive layer along the entire bond length [1]. Anchors used in post-installed anchorage are classified into two main categories: mechanical anchor and adhesive anchor. Comparing with the mechanical anchor, adhesive anchors have greater capacity and better viability because of sufficient embedment depth and uniform distribution of bond stress [2]. Considerable efforts are firstly made in order to evaluate the mechanical behavior of post-installed anchors in concrete at room temperature [3-5].

For the actual performance of steel-to-concrete connection by post-installed anchorage, only little literary is found. Cook RA [6] investigated experimentally the behavior of steel-to-concrete connection with multiple anchors subjected to shear and moment. Xie Q [7] studied the performance of post-installed anchorage between steel and concrete subjected to shear and moment and it was concluded that anchorage failure is governed by yield and fracture of bonded-in reinforcements. Xu L [8] adopted FEA method to study the seismic behavior of post-installed anchorage between steel and concrete, the results showed that the anchorage joint with edge distance of $8 \mathrm{~d}$ and spacing of $12 \mathrm{~d}$ for bonded-in reinforcements behave good performance in load bearing capacity and energy dissipation. The design criteria for post-installed anchorage of steel-to-concrete connection was reviewed and it was noticeable that the failure mode depend largely on the design criteria [9]. Fire is also a potential hazard which should be considered in post-installed anchorage design. Comparing with inorganic adhesives, organic adhesives are more sensitive to temperature effects [10-11]. The post-fire 
mechanical performance of inorganic adhesive anchors was evaluated experimentally, it was found the pull out capacity decrease significantly when temperature of inorganic adhesive is rise to $300^{\circ} \mathrm{C}$ [12].

The existing studies about high temperature mechanical behavior of post-installed anchorage mainly focus on the pull out performance of single anchor or bonded-in reinforcement. In order to investigate the high temperature mechanical behavior of post-installed anchorage between steel and concrete, several 3D joint models of I-shaped steel beam connecting to concrete base are established by ABAQUS, two parameters, the thickness of fire protection and embedment depth of bonded-in reinforcements, is analyzed.

\section{Model details}

A typical joint model composed by I-shaped steel beam, concrete base, four bonded-in reinforcements and steel plate are established which is shown in Fig. 1. All steel elements are enclosed by fire protection and a serious of thickness value including $25 \mathrm{~mm}, 30 \mathrm{~mm}, 35 \mathrm{~mm}, 40 \mathrm{~mm}, 45 \mathrm{~mm}, 50 \mathrm{~mm}$, $55 \mathrm{~mm}$ and $60 \mathrm{~mm}$ are considered. The spacing and edge distance is kept as a constant of $200 \mathrm{~mm}$ and $50 \mathrm{~mm}$ respectively. The concrete base is reinforced with $8 \mathrm{~mm}$ and $20 \mathrm{~mm}$ reinforcements. The diameter of bonded-in reinforcement is $16 \mathrm{~mm}$. The embedment depth is $15 \mathrm{~d}, 20 \mathrm{~d}$ and $25 \mathrm{~d}$. The basic information of joint models is listed in Table 1.

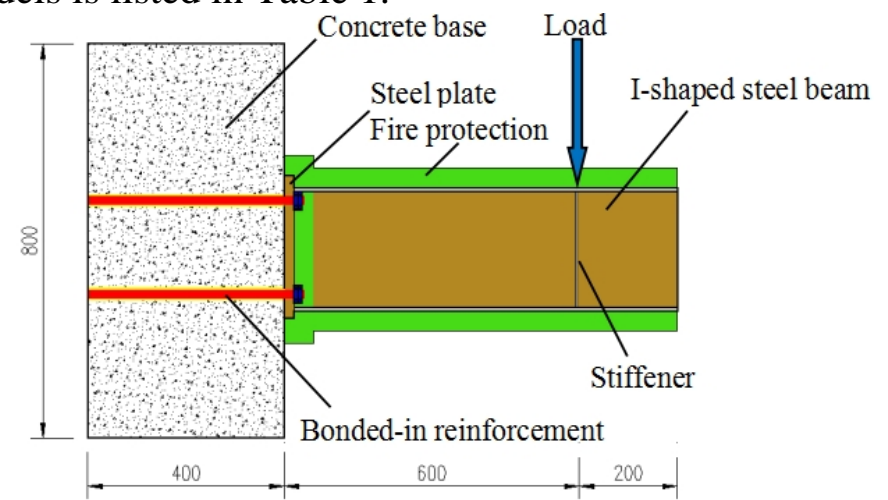

Fig. 1 The configuration details of joint

Table 1 Basic information of joint model [unit: $\mathrm{mm}$ ]

\begin{tabular}{lccccc}
\hline Components & Concrete base & \multicolumn{2}{c}{ I-shaped steel beam } & \multirow{2}{*}{$\begin{array}{c}\text { Steel anchor } \\
\text { plate }\end{array}$} \\
\cline { 3 - 5 } & & $\begin{array}{c}\text { Overall } \\
\text { dimension }\end{array}$ & $\begin{array}{c}\text { Web } \\
\text { thickne } \\
\text { ss }\end{array}$ & $\begin{array}{c}\text { Flange } \\
\text { thickness }\end{array}$ & \\
\hline Dimensions & $500 \times 400 \times 800$ & $800 \times 118 \times 250$ & 10 & 10 & $300 \times 300 \times 20$
\end{tabular}

The elastic modulus and yield strength of steel is 2.1x105 MPa and $360 \mathrm{MPa}$ respectively, linear harden model has been considered in stress-strain relationship of steel. Damage-plastic model has been adopted for concrete base with compressive strength of $30 \mathrm{MPa}$, the elastic modulus is 3.0x104 $\mathrm{MPa}$ and Poisson's ratio is 0.2. The element C3D8 is used for steel I-beam and bonded-in reinforcements in model while C3D8R element for concrete base. Binding constraint is considered to simulate the connection between steel plate and bonded-in reinforcements and hard contact is used to analyze the interaction between steel plate and concrete base surface. The natural fire curve is adopted for heating test. It is postulated that the bottom and two sides of steel beam is exposed to fire for two hours. To evaluate the residual bearing capacity, the vertical load is subsequently applied at the flange of steel beam up to failure where the $5 \mathrm{~mm}$ thickness stiffener is used to prevent the local buckling. 


\section{Analysis results}

Two factors have been considered in this analysis: thickness of fire protection and embedment depth of bonded-in reinforcements. Six models whose fire protection thickness is $25 \mathrm{~mm}, 30 \mathrm{~mm}, 35 \mathrm{~mm}$, $40 \mathrm{~mm}, 45 \mathrm{~mm}, 50 \mathrm{~mm}, 55 \mathrm{~mm}$ and $60 \mathrm{~mm}$ respectively are founded. The temperature field of model and the time-history curves of maximum temperature at bonded-in reinforcements are shown in Fig. 2 and Fig. 3. It can be observed an obvious temperature gradient at I-shaped steel beam. The working temperature for cement-based inorganic adhesive with $15 \mathrm{~d}$ embedment depth should be controlled below $250^{\circ} \mathrm{C}$ according to literature [12]. The maximum temperature of bonded-in reinforcements could be controlled below $250^{\circ} \mathrm{C}$ if the thickness of fire protection is added up to $40 \mathrm{~mm}$. A calculation method as Eq. 1 is proposed to predict the maximum temperature of bonded-in reinforcements. Where ${ }^{T_{\max }}$ means the maximum temperature of bonded-in reinforcements and ${ }^{t}$ is the thickness of fire protection. The comparison of calculated value and numerical value is depicted in Fig. 4.

$$
T_{\max }=54.238 t+3.424 \text {. }
$$

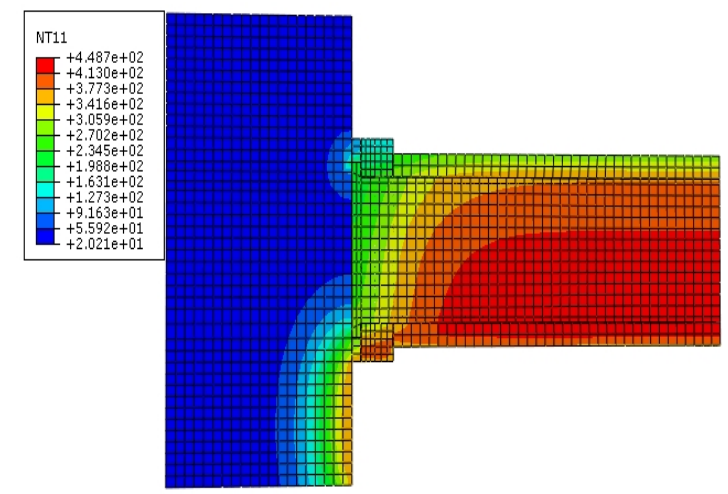

Fig. 2 The temperature field

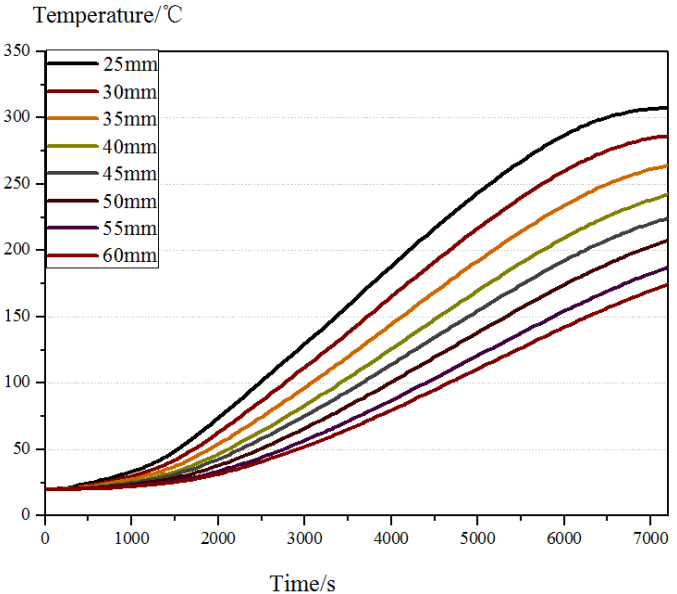

Fig. 3 The time-history curves of maximum temperature

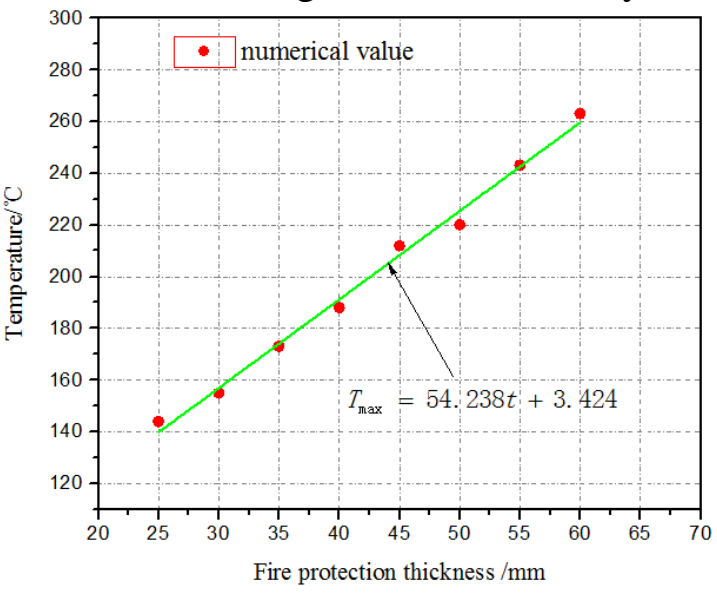

Fig. 4 Comparison of calculated value and numerical value

The load-displacement curves at loading point are presented in Fig. 5. At the initial loading stage, the displacement was small and behaved in a linear elastic manner until the yield of bonded-in reinforcements. Afterwards, the displacement developed faster with the increase of load, the load-displacement curves became non-linear. This trend was observed for all models, which represented the deduction of flexural stiffness due to yield of bonded-in reinforcements. The deformation of bonded-in reinforcement in tensile zone was then developed rapidly until anchorage failure. It can be concluded both larger embedment depth and thicker fire protection can improve the residual bearing capacity after fire by comparison among models with different embedment depth and fire protection thickness. 


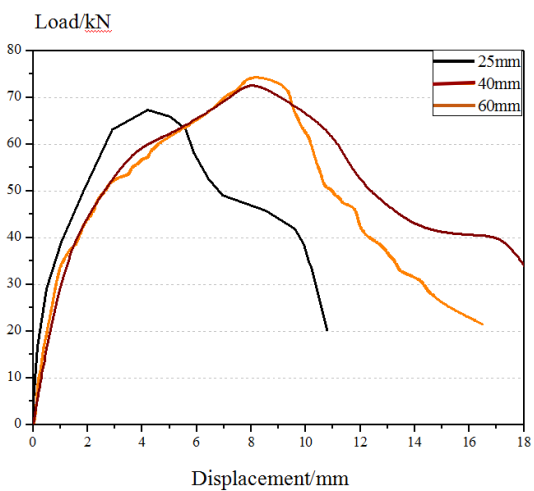

(a) $25 \mathrm{~d}$

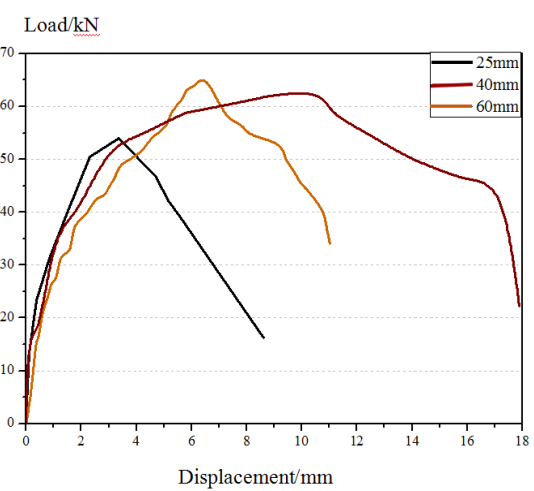

(b) $20 \mathrm{~d}$

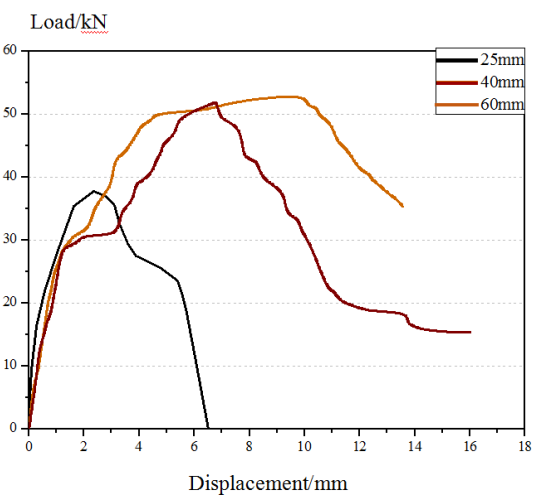

(c) $15 \mathrm{~d}$

Fig. 5 Load-displacement curves at loading point

The residual bearing capacity is showed in Fig. 6 . When the fire protection thickness is $40 \mathrm{~mm}$, the residual bearing capacity of the $20 \mathrm{~d}$ model is $62.8 \mathrm{KN}$ and increases by $21 \%$ compared with the $15 \mathrm{~d}$ model. The residual bearing capacity of the $25 \mathrm{~d}$ model is $73.8 \mathrm{KN}$ and increases by $18 \%$ compared with the $20 \mathrm{~d}$ model. For the model with $25 \mathrm{~mm}$ thickness fire protection and $15 \mathrm{~d}$ embedment depth, the I-shaped steel beam deformed largely and inorganic adhesive lost its bond performance after two hours which leads to more reduction on residual bearing capacity and steeper descent branch.

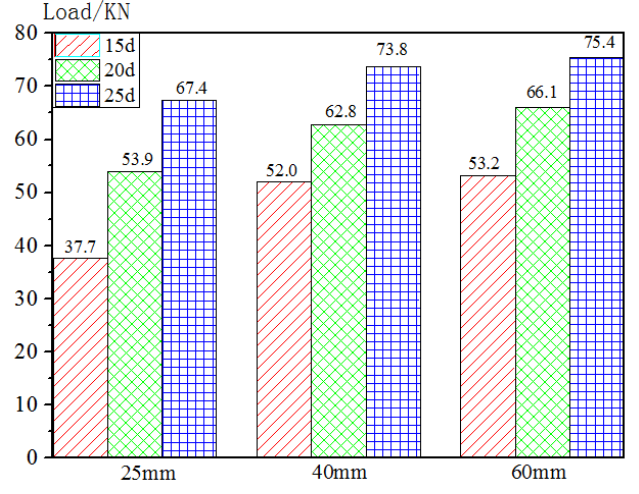

(a) Comparison among different embedment depth

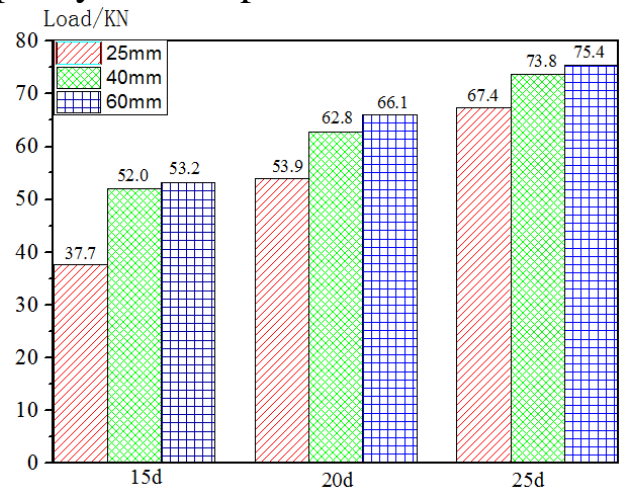

(b) Comparison among different fire protection

Fig. 6 the residual bearing capacity of joint

The longitudinal displacement of bonded-in reinforcements is presented in Fig. 7. The maximum longitudinal displacement is $20.2 \mathrm{~mm}, 9.16 \mathrm{~mm}$ and $6.22 \mathrm{~mm}$ for $15 \mathrm{~d}$, $20 \mathrm{~d}$ and $25 \mathrm{~d}$ model respectively. Shear deformation occurs obviously at bonded-in reinforcement of compressive zone for $25 \mathrm{~d}$ model which possesses the higher residual bearing capacity. It can be concluded that the employment of inorganic adhesive has been verified to be an effective method to improve bond performance between bonded-in reinforcements and concrete under high temperature.

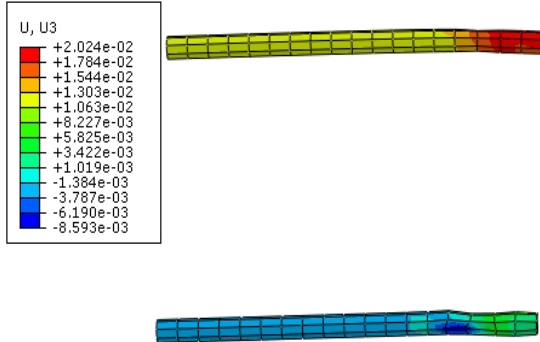

(a) $15 \mathrm{~d}$

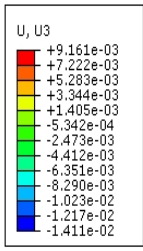

(b) $20 \mathrm{~d}$
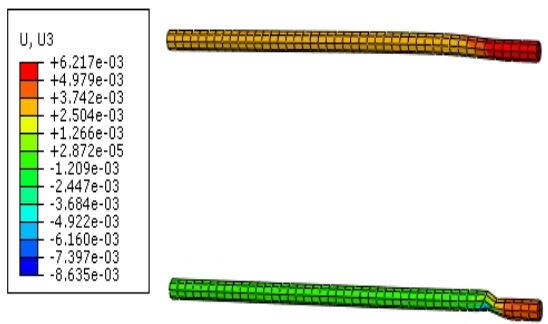

(c) $25 \mathrm{~d}$

Fig. 7 The longitudinal displacement of bonded-in reinforcements

\section{Conclusions}

To investigate the mechanical behavior of post-installed anchorage between steel and concrete under high temperature, several 3D joint models are employed to give numerical analysis and the results can 
be shown as following:

(1) The maximum temperature of bonded-in reinforcements could be controlled below $250^{\circ} \mathrm{C}$ if the thickness of fire protection is added up to $40 \mathrm{~mm}$. So the thickness of fire protection is suggested considering in reasonable fire resistant design to keep the bond strength of inorganic adhesive. A calculation method is proposed to predict the maximum temperature of bonded-in reinforcements.

(2) Both larger embedment depth and thicker fire protection can improve the residual bearing capacity after fire by comparison among models with different embedment depth and fire protection thickness. When the fire protection thickness is $40 \mathrm{~mm}$, the residual bearing capacity of the $20 \mathrm{~d}$ model is $62.8 \mathrm{KN}$ and increases by $21 \%$ compared with the $15 \mathrm{~d}$ model. The residual bearing capacity of the $25 \mathrm{~d}$ model is $73.8 \mathrm{KN}$ and increases by $18 \%$ compared with the $20 \mathrm{~d}$ model. The maximum longitudinal displacement is $20.2 \mathrm{~mm}, 9.16 \mathrm{~mm}$ and $6.22 \mathrm{~mm}$ for $15 \mathrm{~d}, 20 \mathrm{~d}$ and $25 \mathrm{~d}$ model respectively. The employment of inorganic adhesive has been verified to be an effective method to improve the bond performance between bonded-in reinforcements and concrete under high temperature.

\section{Acknowledgements}

This work was financially supported by the Natural Science Foundation in Shandong Province of China (Grant no. ZR2014EL037) and the Education Foundation for Scientific and Technological Projects in Colleges and Universities in Shandong Province of China (Grant no. J13LG06).

\section{References}

[1] P. Upadhyaya, S. Kumar: International Journal of Adhesion \& Adhesives Vol. 60 (2015), p. $54-62$

[2] Guideline for European Technical Approval of Metal Anchors for Use in Concrete Annex C: Design Methods for Anchorages, European Organization for Technical Approvals, Brussels, 1997

[3] R.A. Cook, G.T. Doerr, R.E. Klingner: Aci Structural Journal Vol. 90 (1993), p. 514-524

[4] R.A. Cook: Journal of Structural Engineering Vol. 119 (1993), p. 2744-2762

[5] R. Eligehausen, J. Appl, R.A. Cook: Aci Structural Journal Vol. 103 (2006), p. 822-831

[6] R.A. Cook, R.E. Klingner: Journal of Structural Engineering Vol. 118 (1992), p. 1645-1665

[7] Q. Xie, Z.D. Lu: Journal of Building Structures Vol. 28 (2007), p. 247-251 (In Chinese)

[8] L. Xu, Q. Xie, C.L. Sun: International Journal of Engineering and Technology Vol. 9 (2017), p. 189-193

[9] V. Mahadik, A. Sharma, J. Hofmann, in: Proceedings of the 2017 fib Symposium, held in Maastricht, The Netherlands, June 12-14, (2017), p. 1033-1040

[10] Y. Zhang, G.B. Lou, K.P. Chen, et al: Fire Technology Vol. 52 (2016), p. 877-895

[11] X. Wang, C.J. Jiang, K.Z. Zhao, et al: Advanced Materials Research Vol. 674 (2013), p. $1877-1882$

[12] Y.Q. Zhao: Bond Behavior of Post-installed Reinforcement with Inorganic Adhesive after High Temperature, the University of Jinan, Ji`nan, China: 2015 (In Chinese) 